\title{
SOB A PELE: IMPLANTES SUBCUTÂNEOS, HORMONIOS E GÊNERO
}

\author{
Daniela Manica* \\ Universidade Federal do Rio de Janeiro - Brasil \\ Marina Nucci** \\ Fundação Oswaldo Cruz - Brasil
}

Resumo: Neste artigo, discutimos o desenvolvimento dos implantes subcutâneos de hormônios. Após apresentar alguns dos elementos e controvérsias que envolveram seu surgimento no Brasil, e partindo da atuação do médico baiano Elsimar Coutinho para esse processo, ressaltamos a estabilização desse formato alternativo de administração de hormônios: a via subcutânea. Discutimos a atualização da sua nomeação como "chips", explorando algumas conexões com o anúncio de pesquisas envolvendo o desenvolvimento tecnológico da via subcutânea, das atuais cápsulas de silicone microporoso para placas de silício e titânio, ativáveis por redes de dados digitais. Tomando como foco o laboratório brasileiro de manipulação Elmeco, que produz implantes há várias décadas, discutimos as diversas formulações de hormônios que têm sido disponibilizadas através da via subcutânea. Procuramos demonstrar como a diversidade dos hormônios empregados está pautada por uma imagética binária de gênero, e o quanto o uso dos implantes hormonais mobiliza elementos ligados a masculinidades e feminilidades. Espera-se que a análise desse processo contribua para problematizar dinâmicas do mercado da medicalização e processos vitais ligados a corpos, gênero, sexualidade e reprodução.

Palavras-chave: antropologia da ciência e da tecnologia, gênero, implantes hormonais subcutâneos, medicalização.

Abstract: In this article, we discuss the development of hormone-based subcutaneous implants. After presenting some of the elements and controversies that were implied in

* Contato: danielamanica@ufrj.br

***Em pós-doutoramento. Contato: marinanucci@gmail.com 
implants appearance in Brazil, and taking as a focus the work of the Brazilian M.D. Elsimar Coutinho, we examine the stabilization of this alternative format of hormone delivery: subcutaneous implants. We discuss its re-conceptualization as "chips", exploring the connections with the announcement of researches evolving the technological development of subcutaneous methods, from contemporary silicone capsules to a microchip-based device containing micro-reservoirs that can be activated through a wireless signal. Focusing on Brazilian pharmaceutical laboratory called Elmeco, that has been producing silicone implants for decades, we discuss certain hormone formulations that have been made available subcutaneously. We seek to demonstrate how the diversity of hormones being used is determined by binary gender imagery, and how the use of subdermic hormonal implants mobilizes elements connected to femininities and masculinities. We hope this analysis contributes to problematize market dynamics of medicalization and vital processes connected to bodies, gender, sexuality and reproduction.

Keywords: anthropology of science and technology, gender, hormonal subcutaneous implants, medicalization.

A técnica de administração subdérmica de substâncias vem sendo estudada e empregada para finalidades diversas há algumas décadas. No caso dos hormônios sexuais, a utilização dessas substâncias com finalidades contraceptivas ou de reposição hormonal desenvolveu-se, de maneiras distintas, a partir da segunda metade do século XX, com o conhecimento científico da fisiologia e endocrinologia sexuais e reprodutivas (Oudshoorn, 1999).

Formas eficientes de sintetizar, dosar e administrar hormônios com finalidades diferentes compuseram uma das principais preocupações da indústria farmacêutica nas últimas décadas. Mais de 50 anos após a descoberta e estabilização do primeiro anticonceptivo hormonal oral (a "pílula"), a gestão da fecundidade contemporânea inclui a utilização de hormônios por vias diversas (oral, intramuscular, vaginal, cutânea e subcutânea). Parte dessas técnicas foi desenvolvida com financiamento de instituições internacionais no contexto das preocupações com a "explosão demográfica", sobretudo nos países do Terceiro Mundo, como o Population Council, OMS, US-AID (Corrêa, 1998; Fonseca Sobrinho, 1993). Buscava-se, então, desenvolver maneiras de administração de contraceptivos que tivessem como resultado um controle eficaz da fertilidade, em níveis populacionais. 
Neste artigo, discutimos o desenvolvimento de uma dessas tecnologias alternativas, a dos implantes subcutâneos contraceptivos, e exploramos as concepções de gênero e sexualidade presentes no processo de estabilização dessa tecnologia, e de medicalização dos corpos através do uso de hormônios sexuais. $^{1}$

O texto está dividido em seis subitens: implantes subcutâneos; microchips; implantes como "chips": tecnologia contraceptiva e o mercado da saúde; hormônios sexuais, aprimoramento e a tecnopolítica dos corpos; os usos de hormônios androgênicos em implantes subcutâneos; e, por fim, implantes, hormônios e a microprostética de gênero.

Apresentamos, então, o histórico do desenvolvimento dos implantes, partindo da atuação do médico baiano Elsimar Coutinho no seu desenvolvimento, ${ }^{2}$ e levando em conta as controvérsias que ocorreram no Brasil acerca desse tipo de tecnologia, subcutânea, e sua biopolítica. Posteriormente, mostramos como a temática (e algumas polêmicas) da via subcutânea foi recentemente atualizada pela realização de pesquisas com microchips de silício e titânio, ativáveis por redes de dados digitais. Argumentamos, então, que embora esses chips ainda estejam em desenvolvimento, no imaginário brasileiro acerca dessa via, a terminologia "chip" aparece como uma forma de se referir aos implantes de silicone. Essa apropriação enfatiza um caráter de "alta tecnologia" aos implantes subcutâneos, que se articula, como procuramos demonstrar, com os processos de medicalização em curso, e de aprimoramento do corpo e da sexualidade, extrapolando os propósitos iniciais dessas substâncias, subscritas à

\footnotetext{
Este texto utiliza trechos reformulados da tese de doutorado de uma das autoras (Manica, 2009). O artigo procura trazer uma atualização da questão da produção e comercialização dos implantes subcutâneos e uma discussão sobre o desenvolvimento da tecnologia dos implantes com microchips. Resulta, portanto, de uma pesquisa realizada por ambas as autoras ao longo dos anos 2015 e 2016.

2 Coutinho se tornou mais conhecido no Brasil após a publicação do livro Menstruação, a sangria inútil (Coutinho, 1996), no qual defende a utilização ininterrupta de hormônios com finalidades contraceptivas. Sua formação como pesquisador coincide com o momento de efervescência em busca de técnicas variadas que possibilitassem o "controle da natalidade" - expressão que, posteriormente, foi substituída pela de "planejamento familiar". Ele esteve envolvido, como jovem professor e pesquisador na Universidade Federal da Bahia, em pesquisas sobre fisiologia reprodutiva, que acabaram levando à revelação dos efeitos contraceptivos de uma substância derivada da progesterona, em meados da década de 1960. Esse hormônio acabou sendo empregado como um contraceptivo injetável de depósito (de uso mensal ou trimestral), processo que envolveu diversos embates e polêmicas (Corrêa, 1998; Manica, 2009; Vecchio, 1993). Atualmente esse método está presente no mercado brasileiro, disponibilizado por laboratórios farmacêuticos. Seu nome comercial mais conhecido é Depo-Provera (Manica, 2003).
}

Horizontes Antropológicos, Porto Alegre, ano 23, n. 47, p. 93-129, jan./abr. 2017 
contracepção e reposição hormonal. Nesse processo, são ressaltadas e problematizadas algumas das formas de divulgação dos implantes hormonais produzidos no Brasil pelo laboratório de manipulação Elmeco.

\section{Implantes subcutâneos}

As pesquisas com implantes subcutâneos em Salvador foram iniciadas por Coutinho no final da década de 1960, a partir de um convênio com o Population Council - instituição fundada naquela época para recolher recursos de agências de financiamento (como a Fundação Ford e a Rockefeller) para a realização de pesquisas clínicas na área da contracepção. Em sua autobiografia, Coutinho fala amplamente sobre essa aliança, da qual participava também o diretor da divisão médica do Population Council, Sheldon Segal, e relata o início das pesquisas pioneiras com implantes subcutâneos de acetato de megestrol em Salvador por volta de 1968 (Coutinho, [s.d.]).

Coutinho coordenou uma equipe de pesquisas com implantes subcutâneos do International Committee for Contraceptive Research (ICCR). Ao propor o uso dos implantes, defendia-se o benefício de eles possibilitarem uma dosagem hormonal muito inferior às diárias ingeridas com a pílula. Assim como os dispositivos intrauterinos e contraceptivos injetáveis, a técnica dos implantes condensava alguns dos objetivos procurados para os contraceptivos em desenvolvimento: a ação por um longo período e o pouco "controle" por parte da usuária na sua administração (sobretudo a interrupção do uso).

Talvez justamente por conjugar de maneira eficaz essas duas características almejadas (ação prolongada + pouco controle da usuária), a técnica dos implantes contraceptivos no Brasil teve uma trajetória marcada por controvérsias. ${ }^{3}$ Como veremos a seguir, diversos embates em torno das pesquisas clínicas com contraceptivos e dos programas de planejamento familiar nos países do hemisfério sul expunham as tensões subjacentes aos efeitos biopolíticos da contracepção, e as relações entre população, desenvolvimento e reprodução que as fundamentavam. No final da década de 1970 e começo dos anos 1980, explicitavam-se as articulações para que a contracepção se configurasse como

3 Ana Lima Pimentel atualmente desenvolve pesquisa de doutorado no Instituto Fernandes Figueira (IFF/ Fiocruz) sobre implantes contraceptivos no Brasil. 
um recurso possível para o controle eficaz da natalidade, principalmente das populações pobres dos países em desenvolvimento.

Os movimentos sociais em defesa da saúde da mulher consolidaram-se no Brasil a partir dos anos 1985 e 1986, com a abertura democrática. Considerando aspectos bioéticos das pesquisas clínicas e os propósitos biopolíticos ligados ao controle da natalidade, movimentos feministas estiveram ativamente empenhados na denúncia e na proibição dessas pesquisas. A elaboração do Programa de Assistência Integral à Saúde da Mulher (PAISM), a instituição do Conselho Nacional dos Direitos da Mulher, e a I Conferência Nacional de Saúde e Direitos da Mulher foram eventos contemporâneos que representavam a entrada dessas questões numa agenda de discussões (Berquó, 2003; Corrêa, 1998; Osis, 1994, 1998).

No que diz respeito à contracepção, buscava-se um "desentranhamento" em relação a intenções ou projetos políticos que envolvessem o controle da natalidade e que desrespeitassem aquilo que se configurou em torno das definições de "saúde e direitos sexuais e reprodutivos". Contra as iniciativas "controlistas" ou "antinatalistas" (Fonseca Sobrinho, 1993) articulou-se, por exemplo, a Rede de Defesa da Espécie Humana (REDEH) - que tomou como uma de suas frentes de luta as pesquisas sobre os efeitos do Norplant (Dacach; Israel, 1993, p. 57). ${ }^{4}$ O Norplant foi o primeiro implante subcutâneo produzido pela indústria farmacêutica, e compreende um conjunto de bastonetes de silicone microporoso, que contêm o hormônio levonorgestrel, com ação contraceptiva.

Além de tornar mais explícito o aspecto biopolítico da tecnologia dos implantes, frequentemente invisibilizado pelo argumento do "desenvolvimento científico" ou da "democratização do acesso à contracepção", Dacach e Israel apresentam relatos sobre os procedimentos de pesquisas clínicas com esses contraceptivos nos países em desenvolvimento.

Citam, para tanto, os relatórios do Population Council sobre as pesquisas com o Norplant na Indonésia. Estudados pela feminista Betsy Hartman, os

\footnotetext{
4 As autoras localizavam as pesquisas clínicas com o Norplant no âmbito dos inúmeros investimentos feitos por diversas instituições internacionais para tratar do que se configurava como o problema da explosão demográfica nos países do Terceiro Mundo. Evidenciavam, com isso, as rotas internacionais que envolviam a realização de pesquisas científicas sobre contracepção e a implantação de programas de planejamento familiar.
}

Horizontes Antropológicos, Porto Alegre, ano 23, n. 47, p. 93-129, jan./abr. 2017 
relatórios mostravam: recomendações para implantar o Norplant nas mulheres que quisessem, sem discutir outras opções (cf. Dacach; Israel, 1993, p. 27); evidências de que alguns talvez tenham sido implantados sem saber se a paciente estava ou não grávida (cf. Dacach; Israel 1993, p. 28); a expectativa de que os implantes fossem mantidos por cinco anos, e a ausência da discussão sobre a questão da remoção - as usuárias "davam a sua palavra" e seriam "lembradas disso" caso solicitassem a retirada do implante (cf. Dacach; Israel, 1993, p. 28); que as informações sobre efeitos colaterais eram restritas porque "muita informação poderia amedrontar as mulheres da área rural e desencorajar o uso do Norplant" (cf. Dacach; Israel, 1993, p. 28); e, finalmente, que $40 \%$ das usuárias relataram uma dor terrível durante a remoção (cf. Dacach; Israel, 1993, p. 29).

Ao falar sobre os potenciais abusos na utilização do Norplant, Dacach e Israel dão, ainda, alguns exemplos da sua indicação nos Estados Unidos como instrumento de penalização ou punição - como, por exemplo, no caso de um juiz na Califórnia que ordenara o seu uso para uma mulher acusada de maus tratos ao filho ${ }^{5}$ - e de "redenção" ou "premiação" para determinadas pessoas - como um legislador no estado de Kansas que propôs às beneficiárias da Previdência que aceitassem o Norplant, um pagamento de US\$ 500 e, depois, US\$ 50 por ano. ${ }^{6}$

O Norplant foi um dos primeiros implantes produzidos por laboratórios farmacêuticos a ser estudado para disponibilização no mercado brasileiro. No entanto, em virtude das mobilizações contrárias, suas pesquisas clínicas acabaram sendo proibidas no Brasil na década de 1980, bem como sua aprovação posterior (Corrêa, 1994; Dacach; Israel, 1993; Manica, 2009). Apesar da não aprovação do Norplant no Brasil, desde 1999 o laboratório farmacêutico Organon comercializa outro implante contraceptivo com um hormônio similar (etonorgestrel), chamado Implanon, cuja duração é de até três anos (Manica, 2003).

A despeito dos embates e do cenário politicamente carregado no que diz respeito à disponibilização dos implantes subcutâneos contraceptivos no mercado farmacêutico brasileiro, eles compuseram parte importante das pesquisas

5 New York Times, 19 de outubro de 1991 (cf. Dacach; Israel, 1993, p. 31).

6 New York Times, 29 de novembro de 1991 (cf. Dacach; Israel, 1993, p. 32). 
das quais Elsimar Coutinho participou em sua carreira científica. Mais do que isso, tornaram-se a principal indicação para o tratamento clínico de suas pacientes nas últimas décadas. ${ }^{7}$

A especificidade do atendimento de Elsimar Coutinho em seus consultórios particulares (que mantém em diversas capitais brasileiras) ${ }^{8}$ depende, fundamentalmente, da produção desses implantes subcutâneos pela Elmeco, ${ }^{9}$ laboratório de manipulação construído dentro do Centro de Pesquisas e Assistência em Reprodução Humana (Ceparh), que mantém em Salvador. ${ }^{10}$

Tendo adquirido o know-how a partir de pesquisas com os mais variados hormônios, e frustradas as tentativas iniciais de patenteamento ou produção industrial desses implantes, Coutinho optou por uma produção em pequena escala e pela comercialização desses implantes a um custo mais alto, cuja recomendação é feita de forma "individualizada". Sua presença frequente na mídia, as publicações de livros como o Menstruação, a sangria inútil (Coutinho, 1996) e o testemunho de pacientes/personalidades do meio artístico colaboraram para a valorização do seu atendimento clínico, e do uso desses implantes.

A Elmeco consiste em um laboratório de manipulação para a produção dos implantes hormonais. Conta com uma pequena equipe de técnicos (em geral, mulheres) que produzem as diferentes modalidades de implantes hormonais disponíveis para tratamento: gestrinona, testosterona, levonorgestrel, estradiol, nestorone (elcometrina) e acetato de nomegestrol. Os hormônios, comprados em pó e em quantidades maiores da indústria química, são introduzidos manualmente (Figura 1) em cada tubo de silicone microporoso (polidimetilsiloxano). Esses tubos são selados, embalados e esterilizados para posterior distribuição (Manica, 2009). A partir de sua pesquisa de campo em Salvador, Sanabria (2009, p. 179) descreve de maneira pormenorizada o processo de produção desses implantes e discute a especificidade do contexto brasileiro no cenário mundial, com o crescimento do mercado para os laboratórios de manipulação a partir dos anos 1990.

\footnotetext{
Ver http://www.elsimarcoutinho.com/.

8 Coutinho atende em consultórios em cidades como Salvador, São Paulo, Brasília e Rio de Janeiro. No Rio de Janeiro, por exemplo, o consultório está localizado na Torre do Shopping Rio Sul, em Botafogo.

9 O nome do laboratório corresponde à junção das duas primeiras letras do prenome e sobrenomes de Elsimar Metzker Coutinho (ver http://www.elmeco.com.br/). Sobre o seu surgimento, ver o seguinte vídeo: https://www.youtube.com/watch?v=ZaSdLlDzyjQ.

${ }_{10}$ Ver http://ceparh.com.br/.
} 


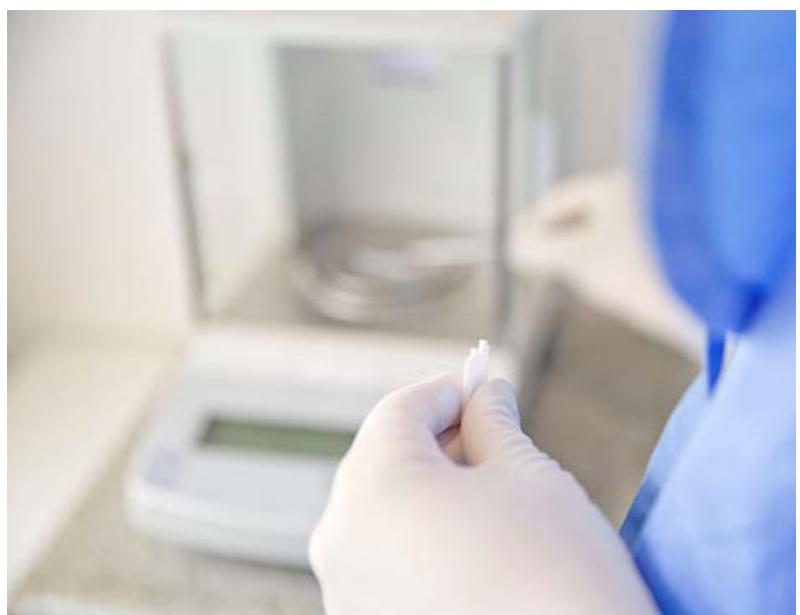

Figura 1. Fotografia do processo de manipulacão dos implantes subcutâneos (fonte: site da Elmeco").

Uma vez prontos, os implantes são distribuídos para o Ceparh e demais consultórios de Coutinho, assim como para profissionais médicos que optem por adotar essa técnica em suas práticas clínicas. De acordo com o boletim de informe técnico ao qual tivemos acesso durante pesquisa realizada entre 2003 e 2009, as principais indicações eram as seguintes: o estradiol, usado para a reposição hormonal em mulheres na menopausa; a testosterona, como complemento na reposição hormonal em mulheres, para tratamento dos sintomas como baixa da libido, depressão e perda de memória, e para reposição hormonal em homens; o levonorgestrel, presente no Norplant, também para reposição hormonal em mulheres, especificamente para as que têm predisposição para "pólipos endometriais"; a gestrinona, usada no tratamento da endometriose e da miomatose (entre outros) e o acetato de nomegestrol, para reposição hormonal, substância registrada por outros laboratórios com os nomes de Surplante e Lutenil. A elcometrina (elmetrin), Nestorone nos Estados Unidos, é um implante semestral que, além de contraceptivo, pode também ser usado nos tratamentos de endometriose e miomatose (Manica, 2009).

11 Ver http://elmeco.com.br/. 
A formalização dessa técnica e o investimento em sua aplicação e reprodutibilidade envolveu tanto a constituição de uma narrativa "oficial" sobre o histórico da produção desses implantes no Brasil (Figura 2), ${ }^{12}$ como a disponibilização periódica de cursos de capacitação que possibilitem a outros médicos a aquisição dessa expertise. ${ }^{13}$

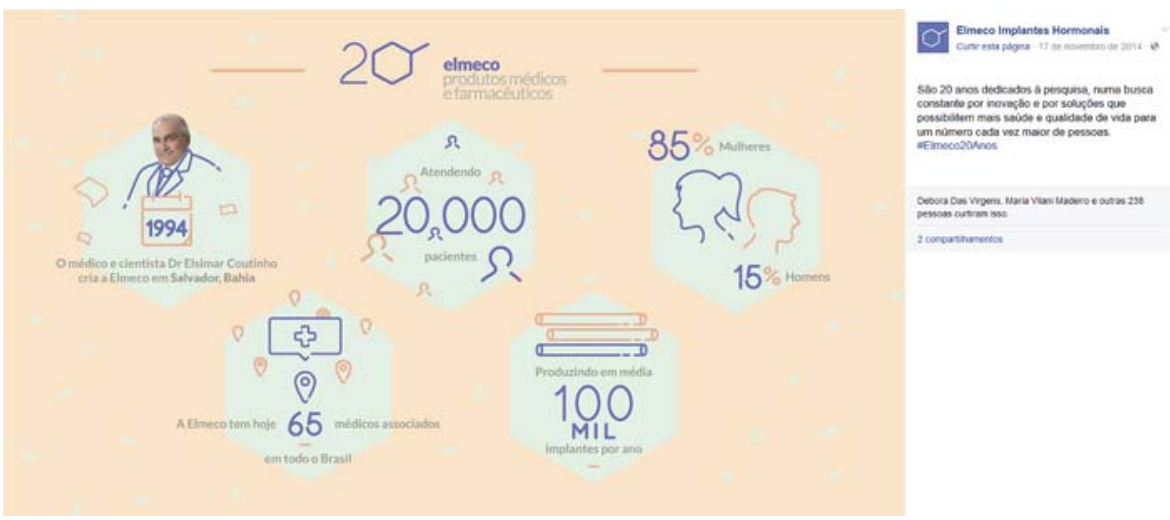

Figura 2. Propaganda da Elmeco (fonte: página da Elmeco no Facebook ${ }^{14}$ ).

A implantação e a retirada das cápsulas de silicone são procedimentos médicos que envolvem o domínio de um aparato técnico e, portanto, uma dinâmica específica entre equipe médica e paciente/usuária, no consultório/ clínica. Do ponto de vista da administração da substância, a rede de relações pressuposta no uso do implante é bastante distinta da que é possível com o uso da pílula oral. Nesse caso, por exemplo, o uso depende de um engajamento diário e consciente por parte da usuária, e sua simples interrupção é suficiente para ela deixar de sentir os efeitos das substâncias ingeridas.

No caso dos implantes, assim como do DIU, que são ambos métodos de ação prolongada, a colocação e a retirada são procedimentos que dependem do aparato do consultório médico ou do sistema de saúde. No contexto das

\footnotetext{
12 Ver também http://www.elmeco.com.br/.

13 Ver http://www.elmeco.com.br/cursos/.

14 Ver https://www.facebook.com/elmeco.
} 
pesquisas clínicas com o Norplant no Brasil, na década de 1980, por exemplo, a menor autonomia das mulheres em relação à tecnologia dos implantes, bem como seu potencial para ser "compulsoriamente" mantido nos corpos femininos, apesar dos efeitos indesejados que estavam sendo relatados, foram fatores que configuraram divergências irreconciliáveis com os movimentos sociais em defesa da saúde da mulher (Corrêa, 1994; Dacach; Israel, 1993). ${ }^{15}$

Apesar de as principais motivações para o desenvolvimento de uma tecnologia como esta, dos implantes subcutâneos, envolver uma biopolítica mais evidente (baixo custo, longo prazo e pouco controle da usuária sobre o método), é curioso que sua estabilização, ao menos no que diz respeito ao mercado brasileiro, tenha se dado nos mercados elitizados de consumo biomédico das grandes cidades brasileiras, e não em programas gratuitos (ou públicos) de planejamento familiar.

A partir da década de 2000, os implantes subcutâneos ressurgem no mercado farmacêutico brasileiro como uma forma segura, eficaz e relativamente duradoura para acessar tratamentos hormonais diversos. Configuraram-se como formas possíveis para a reposição hormonal ou tratamentos de saúde (para endometriose e miomas, por exemplo), e também para "suprimir a menstruação", algo que se torna positivo e desejável (Manica, 2011) ou mesmo um novo "estilo de vida" (Nucci, 2012) para mulheres "modernas" (Manica, 2003).

Tanto em seu formato mercadológico convencional (como o Implanon, disponibilizado pelo laboratório Organon para médicos brasileiros aplicarem em suas pacientes nos consultórios) como nos produzidos pela Elmeco, os implantes passaram a ser apresentados como artefatos de "alta tecnologia" (Sanabria, 2009) para tratamento de questões endocrinológicas. ${ }^{16}$ Possivelmente esse tipo de perspectiva sobre os implantes tenha levado mais recentemente à sua renomeação, em meios de comunicação e pelo senso comum, como "chips" contraceptivos.

\footnotetext{
15 Para mais detalhes sobre os efeitos e desdobramentos desses embates na trajetória de Elsimar Coutinho, ver Manica (2009).

16 Sanabria, contudo, ao descrever o processo de manipulação dos implantes e destacar a sua "formatação" específica (quantidades regulares de hormônios em cada bastonete/implante, por exemplo), ressalta o aspecto artesanal (e portanto low-tech) dessa produção. Defende também, como veremos, que a ideia de que os implantes manipulados são uma forma "individualizada" de atender a uma paciente "sob medida" tem muito mais um efeito retórico do que uma eficácia técnica (Sanabria, 2009, p. 178-179).
}

Horizontes Antropológicos, Porto Alegre, ano 23, n. 47, p. 93-129, jan./abr. 2017 


\section{Microchips}

Em meados de 2014, diversos meios de comunicação internacionais (sites, blogs, revistas, jornais) divulgaram o lançamento, previsto para 2018, de microchips contraceptivos. As páginas internacionais referiam-se especificamente a uma versão digital da técnica de implantes subcutâneos, desenvolvida por uma empresa start-up financiada pela divisão voltada à questão do planejamento familiar da Fundação Bill \& Melinda Gates. Em sua página na internet, a fundação declara ter, como um de seus compromissos, o objetivo de "levar acesso à informação, serviço e suprimentos contraceptivos de alta qualidade para mais de 120 milhões de mulheres e jovens nos países mais pobres até 2020" (tradução nossa). ${ }^{17}$

Também de uso subcutâneo e prolongado, com duração de até 16 anos, e utilizando hormônios similares aos dos implantes inventados na década de 1970, como o levonorgestrel, os microchips atualizam essa discussão sobre a tecnologia dos implantes.

Desenvolvido pela empresa Microchips Biotech, Inc., ${ }^{18}$ especializada em procedimentos de "administração de medicamentos" (drug delivery), os microchips contraceptivos foram anunciados como uma solução prática, de longo prazo, para situações em que é preciso uma administração regular e frequente de substâncias - como, por exemplo, no caso também testado do tratamento da osteoporose com o hormônio teriparatida.

De acordo com a página da empresa, cada implante mede $20 \times 20 \times 7 \mathrm{~mm}$ e contém 200 microrreservatórios, pequenos compartimentos hermeticamente fechados e selados, capazes de armazenar até $1 \mathrm{mg}$ da substância em questão (Figura 3). No caso do levonorgestrel, trabalha-se com uma quantidade de 30 microgramas diários. O implante digital seria ativado por um sinal de rede sem fio, capaz de acionar a liberação da dosagem pré-programada da droga pelo microrreservatório. Além disso, anuncia o site, o implante poderá ser construído com sensores que liberem as substâncias em resposta a mudanças fisiológicas ou metabólicas no paciente. ${ }^{19}$

\footnotetext{
17 Ver http://www.gatesfoundation.org/What-We-Do/Global-Development/Family-Planning.

18 Ver http://microchipsbiotech.com/.

19 Ver http://microchipsbiotech.com/technology.php.
} 


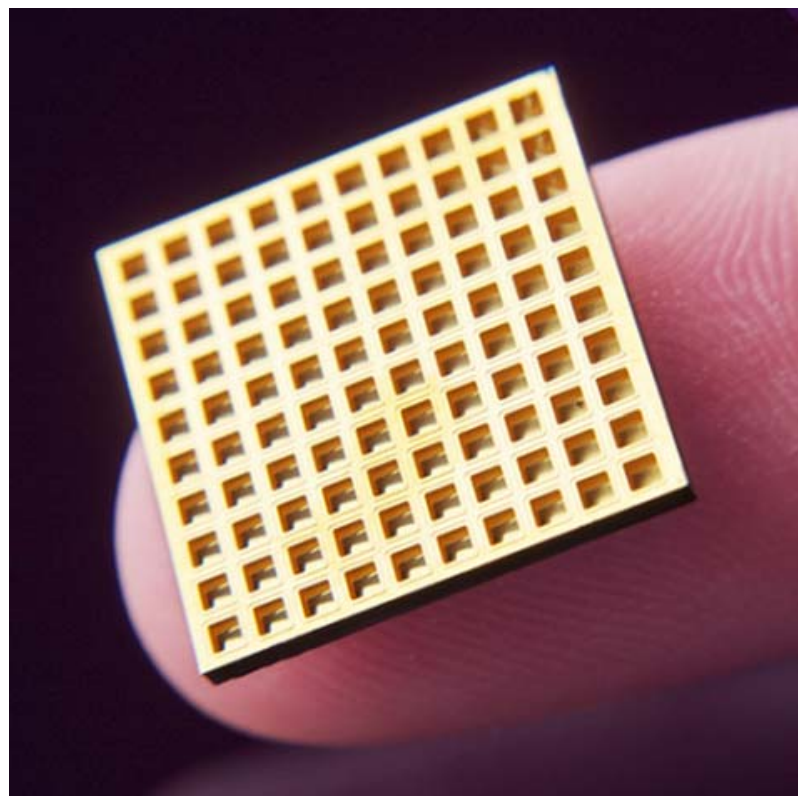

Figura 3. Microchips subcutâneos (fonte: http://microchipsbiotech.com/technology.php).

Comparativamente com os injetáveis e os implantes subcutâneos, a tecnologia dos microchips é apresentada como superior, seja pela durabilidade (de até 16 anos após a inserção), seja pela possibilidade de manejo diário e de interrupções planejáveis pela usuária ou por uma equipe médica sem a necessidade de retirada do dispositivo, ao contrário do que acontece no caso dos implantes de silicone.

Nos blogs e páginas que divulgaram a futura disponibilidade dessa tecnologia (assim como vídeos, programas televisivos e matérias jornalísticas diversas), uma das principais questões levantadas e discutidas foi a segurança da comunicação por via do controle remoto, cujas informações transmitidas fazem disparar a abertura do reservatório. ${ }^{20}$

20 Algumas das matérias consultadas: Kinkead (2014), Lee (2014), McNamee (2015).

Horizontes Antropológicos, Porto Alegre, ano 23, n. 47, p. 93-129, jan./abr. 2017 
A possibilidade de outras pessoas acessarem o dispositivo, provocando ou inibindo a liberação da substância sem o controle/ciência da usuária foi levantada como uma das inseguranças do método. Assim, as críticas abordaram a necessidade, bem como os limites, de uma codificação dos dados dos dispositivos móveis que devem controlar os microchips, problematizando a possibilidade de eles serem invadidos e manipulados por terceiros, em uma espécie de "hackeamento" ovariano (ovarian hacking), inclusive com eventuais objetivos vingativos (revenge pregnancy). Esse desdobramento seria similar ao que se conhece como pornografia de vingança (revenge porn), isto é, a circulação de fotografias e vídeos íntimos por ex-parceiros sexuais pela internet como uma forma de se vingar do final do relacionamento afetivo. A gravidez de vingança seria um recurso (mais) possível ao se obter, sem autorização ou conhecimento da usuária, o controle do dispositivo que acionaria (ou não) a liberação do hormônio contraceptivo. ${ }^{21}$

Por um lado, defende-se a vantagem de um prazo infinitamente maior para o aproveitamento do dispositivo inserido (16 anos no caso do microchip contra 3 a 5 dos implantes de silicone, com quantidades mínimas de uso da substância por dia). Por outro, contudo, a aquisição de um procedimento que envolve a circulação e transmissão de dados que provocam ora a ativação, ora a desativação do dispositivo implica uma série de dúvidas e cautelas acerca de, entre outras coisas, quem pode/consegue acessá-lo.

Em ambos os casos, para implantes e chips, entretanto, há algumas coincidências a destacar. Em primeiro lugar, a presença ativa de instituições filantrópicas preocupadas com questões ecológicas e demográficas, e a dedicação de parte da sua receita ao desenvolvimento dessas tecnologias, ainda que sem garantias óbvias ou imediatas de retorno financeiro. E, em segundo, a realização de pesquisas clínicas em países em desenvolvimento, com uma população-alvo que é vista como carente desses recursos e da solução que eles possibilitam.

${ }^{21}$ Essa questão foi colocada especialmente pelo articulista do Washington Post, Dominic Basulto (2014), mas pode ser vista em várias outras matérias e vídeos produzidos na ocasião em que a tecnologia foi divulgada. Esse estilo de divulgação “pró-polêmica” pode ser pensado como uma espécie de teste sobre a opinião pública acerca do tema. É procedimento bastante frequente como estratégia de marketing e que também foi adotado no surgimento da pílula, na década de 1960 (Tone, 2001; Watkins, 1998). 
Ainda que com a ressalva de que a adesão é "voluntária e sem coerção ou discriminação", é evidente que o público-alvo da divisão de planejamento familiar da Fundação Bill \& Melinda Gates não é o mercado consumidor dos países desenvolvidos, e sim a população pobre dos países do hemisfério sul. As fotografias do site da fundação remetem especificamente a populações africanas. Há uma similaridade gritante com o contexto das pesquisas clínicas realizadas por Coutinho em Salvador (ver Manica, 2009). Esse aspecto é também estudado por Petryna (2009, 2011), que analisa as novas configurações geográficas das pesquisas farmacêuticas e o que chama de expatriação e globalização de ensaios clínicos.

A recorrência dessa mesma estrutura no processo de desenvolvimento dos implantes e dos microchips, como indicam as matérias consultadas, sugerem a permanência da reprodução como uma questão estratégica (Foucault, 1977), e envolvendo um processo crescente de racionalização da reprodução sexual por via da medicalização (Conrad, 2007). Evidencia também o valor dado à reflexão (e atuação) sobre políticas populacionais, seja em escala demográfica, seja pelo processo de responsabilização individual (frequentemente marcado por gênero, raça e orientação sexual) acerca da sexualidade e da reprodução. Essa forma de regulação da fertilidade está incutida nas ideias de "planejamento familiar" e de "regulação ou gestão da fertilidade", que foram sendo desenvolvidas e difundidas concomitantemente à estabilização das técnicas em questão.

O desenvolvimento de tecnologias como os implantes e chips subcutâneos (sem falar das pílulas anticoncepcionais ou mesmo de técnicas esterilizantes como a laqueadura tubária ou a vasectomia) contribui, ao mesmo tempo, para a elaboração de políticas públicas que permitem lidar em níveis macrodemográficos com a questão populacional (Berquó, 2003; Fonseca Sobrinho, 1993; Pitanguy, 1994) e para a especulação e divulgação de tecnologias disponibilizáveis no mercado farmacêutico global.

Contraceptivos com longa duração, como os subcutâneos por exemplo, são especialmente apelativos para programas voltados a populações consideradas "vulneráveis". No Brasil, o Implanon foi adotado em pelo menos duas políticas públicas municipais de saúde: para adolescentes de baixa renda em Porto Alegre (Jardim, 2009) e recentemente pela Secretaria Municipal de Saúde da cidade de São Paulo, com foco especial em "adolescentes com muitos filhos e/ou usuárias de drogas" (Rede..., 2016). 


\section{Implantes como "chips": tecnologia contraceptiva e o mercado da saúde}

A divulgação internacional da tecnologia digital dos chips contraceptivos provocou, no Brasil, uma atualização interessante da discussão sobre os implantes subcutâneos. Os meios de comunicação brasileiros passaram a produzir, principalmente a partir de meados de 2014, várias notícias sobre os "chips" contraceptivos desconsiderando quase que completamente a diferença entre chips e os implantes subcutâneos, isto é, minimizando as alterações que a técnica adquiriu/adquirirá eventualmente com o uso eficaz dos microchips anunciados. Essas matérias representam os implantes de silicone produzidos pela Organon e pela Elmeco como sendo, também, "chips" contraceptivos, ${ }^{22}$ termo que até então não vinha sendo empregado na divulgação dessas técnicas (ver Manica, 2003).

Em muitas dessas matérias de divulgação, os antigos implantes aparecem descritos, inclusive visualmente, como se fossem chips de silício e titânio. No entanto, ao descrever sua disponibilidade no mercado farmacêutico brasileiro e suas formas de uso, fica claro que as matérias se referem aos implantes de silicone.

Podemos dizer, assim, que da perspectiva do mercado brasileiro e do senso comum há uma ênfase na técnica de implantação subcutânea e liberação progressiva de hormônios em detrimento de suas variações tecnológicas, das atualmente disponíveis cápsulas microporosas de silicone aos prometidos microrreservatórios lacrados, (des)ativáveis pela circulação de dados digitais, ou ainda aos chips atualmente utilizados para localização e rastreamento de animais domésticos. O uso do termo "chip" parece conferir aos antigos implantes subcutâneos uma renovação que, embora não seja (ainda) real, é positivada e desejada como se o fosse. ${ }^{23}$

Ambas as versões dos "chips" são interpretadas como formas mais "modernas" ou "tecnológicas" de gerir a fecundidade (Sanabria, 2009), cuja apropriação está sujeita a polêmicas, controvérsias e embates diversos. A ideia

${ }^{22}$ Qualquer busca com “chips anticoncepcionais” em páginas brasileiras traz uma série de exemplos nesse sentido. Para citarmos alguns: Chip... ([s.d.]), Ferreira Junior (2015), Mesquita (2013), Ribeiro (2015), Ventura (2014), Werneck (2013).

23 Sobre as relações entre tecnologia e modernização, e uma crítica ao colonialismo inerente à percepção dessas questões e sua configuração no Brasil, ver Santos (2003). 
subjacente de desenvolvimento e complexidade tecnológica está implicada de maneira mais literal no surgimento anunciado dos microchips contraceptivos. Entretanto, em ambos os processos, as soluções encontradas decorrem de um projeto de fazer convergir trajetórias individuais de fecundidade, desenvolvimento tecnocientífico, capitalismo e planejamentos populacionais e demográficos. Esses dispositivos estabelecem, sobretudo, formas relativamente eficientes de equacionar dinâmicas de consumo e processos vitais, configurando algo próximo ao que Preciado (2013, p. 34-35) caracteriza como o "regime farmacopornográfico".

Em contraposição às demais técnicas contraceptivas, o apelo aos implantes subcutâneos articula-se à expectativa de uma maior capacidade de individualizar e personalizar a quantidade e o tipo dos hormônios que serão implantados em cada paciente, diferentemente do padrão "massificado" dos outros métodos comercializados pela indústria farmacêutica multinacional.

Essa capacidade de "personalização" é frequentemente explorada por Elsimar Coutinho e outros médicos que trabalham com ele nas reportagens veiculadas na mídia, mas também no site da Elmeco e em seus sites individuais. Malcolm Montgomery, ${ }^{24}$ por exemplo, se refere aos implantes como uma pílula "moderna e melhorada", capaz de ser modelada para cada mulher a partir de seu peso, altura, hábitos alimentares e a frequência de realização de atividades físicas. Além disso, a "personalização" das doses hormonais contidas nos implantes também se relaciona com a ideia de um "atendimento personalizado" ou "atendimento VIP", somado ao fato de esses médicos aparecerem com frequência na mídia televisiva, e que seus consultórios - em diferentes capitais do país - se localizam em áreas nobres da cidade, com consultas caras e concorridas. ${ }^{25}$

A estratégia de explorar a capacidade de "personalização" dos implantes está ligada à especificidade de a Elmeco se apresentar como farmácia de manipulação. Sanabria (2009) problematiza a relação entre a expansão do mercado dos laboratórios de manipulação e a ideia a "individualização" do medicamento pressuposta nesse tipo de condicionamento da substância. Considera ainda que a técnica de manipulação supostamente permitiria uma maior autonomia

\footnotetext{
24 Ver http://www.drmm.com.br.

${ }^{25}$ No consultório de Coutinho no Rio de Janeiro, por exemplo, é necessário agendar a consulta com, em média, três meses de antecedência. Cada consulta custa no mínimo R \$ 600,00 (valor em fevereiro de 2016) e com a colocação dos implantes os valores podem passar de R $\$ 3.000,00$.
} 
aos médicos na prescrição das quantidades dos respectivos princípios ativos, escapando da lógica impessoal e generalizante dos medicamentos comercializados pelos laboratórios farmacêuticos convencionais, multinacionais e cuja escala de circulação é global. Contudo, no caso dos implantes, Sanabria (2009, p. 180) aponta que as quantidades de substâncias obedecem também uma certa padronização, o que sugere que essa individualização esteja condicionada a essa limitação e que seja muito mais da ordem do discurso e de uma expectativa que tem a ver com um estilo de consumo mediado pela classe social.

Embora Sanabria aponte a ampliação do mercado das farmácias de manipulação no Brasil, brecha que tornou possível o crescimento de laboratórios como a Elmeco, a lógica de "personalização" dos medicamentos manipulados segue na contramão das tentativas de regulamentação da Agência Nacional de Vigilância Sanitária (Anvisa). Da perspectiva da própria agência, a existência desse sistema no mercado brasileiro é controversa.

Em documento publicado em 2005, Subsídios à discussão sobre a proposta de regulamentação para farmácias magistrais, a agência defende que os medicamentos industriais seriam mais seguros, pois passariam por procedimentos rígidos de controle e verificação de qualidade. Os medicamentos manipulados seriam menos regulados, já que testes para verificar sua qualidade seriam praticamente inviáveis, deixando o usuário final mais exposto a possíveis erros não detectados ao longo do processo de fabricação (Agência Nacional de Vigilância Sanitária, 2005; Silva et al., 2010). ${ }^{26}$

Apesar das controvérsias, tanto nas pesquisas clínicas sobre a tecnologia dos implantes, como vimos anteriormente, como nesse caso da regulamentação, ainda pouco consensuada, das farmácias de manipulação, a atuação de Coutinho no desenvolvimento, divulgação e ampliação do mercado de usuárias dos implantes da Elmeco é expressiva.

Talvez em função dessas próprias controvérsias e da instabilidade legal dos implantes e das farmácias de manipulação, o "controle de qualidade" seja um tópico bastante presente no site da Elmeco, que ressalta a exclusividade da empresa, descrita como "uma das únicas farmácias de manipulação de implantes hormonais do mundo". Em sua página na internet, Coutinho

${ }^{26}$ Agradecemos Luiza Lena Bastos (IESC/UFRJ) pela colaboração com as informações a respeito da regulamentação da Anvisa. 
convenientemente divulgou a seguinte fotografia, na qual recebe uma condecoração, como presidente da Elmeco, do "diretor da Anvisa, Dirceu Barbano" (Figura 4). A cerimônia, realizada durante o Fórum da Saúde e Bem-Estar, foi no entanto concebida pelo Grupo de Líderes Empresariais, que se articula em torno do universo empresarial e mercadológico da saúde. ${ }^{27} \mathrm{Na}$ ocasião, um conjunto de médicos brasileiros empreendedores foi selecionado para a premiação.

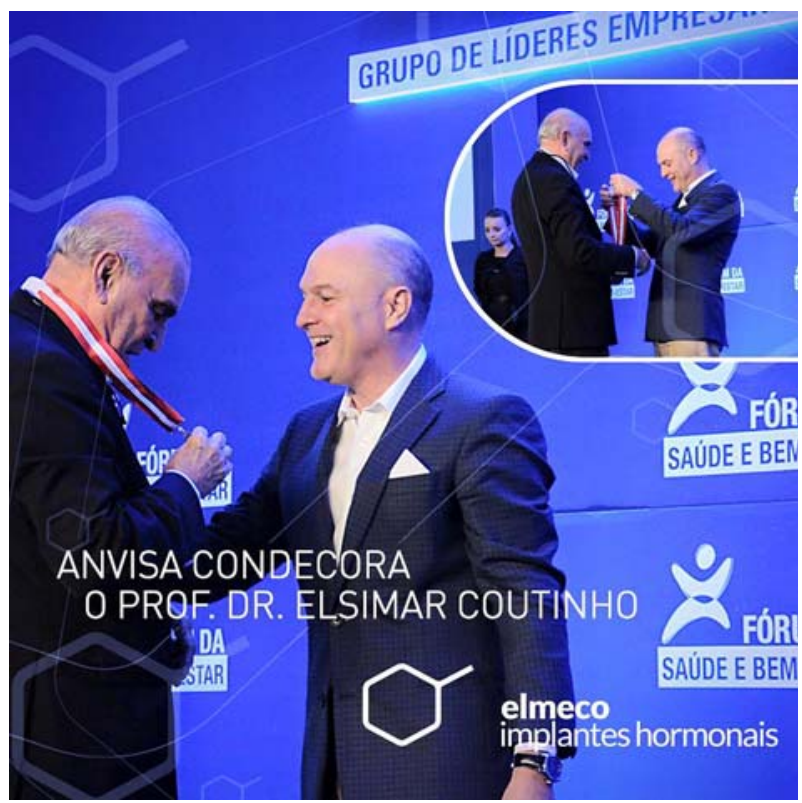

Figura 4. A "condecoracão" pela Anvisa (fonte: site de Elsimar Coutinho $0^{28}$ ).

Hormônios sexuais, aprimoramento e a tecnopolítica dos corpos

Os implantes produzidos pela Elmeco e comercializados por médicos que têm uma circulação frequente nos meios de comunicação, como Elsimar

\footnotetext{
27 Ver http://www.lidebr.com.br/eventos.asp.

${ }_{28}$ Ver http://www.elsimarcoutinho.com/artigos/anvisa-condecora-prof-dr-elsimar-coutinho/.
} 
Coutinho e Malcolm Montgomery ${ }^{29}$ (Nathanson, 2003), são divulgados como tecnologias caras e de ponta. Apesar de a história do desenvolvimento dessa tecnologia estar ligada ao controle da natalidade, os implantes não têm apenas a finalidade de contracepção ou reposição hormonal, mas funcionam também para suprimir a menstruação, incrementar a libido, aumentar a massa muscular e diminuir a celulite. Atrizes e modelos, clientes frequentes nesse circuito, são chamadas a divulgar os benefícios dos implantes. A forma pela qual os implantes subcutâneos - em especial, aqueles produzidos pela Elmeco - são tratados nas reportagens revela também o caráter de "aprimoramento de si" que o seu uso proporciona (Dumit, 2012; Loe, 2001; Mamo; Fishman, 2001; Rose, 2013).

Relacionando-se a um processo mais amplo de "medicalização" (Conrad, 2007) é possível notar contemporaneamente a tendência de criação e multiplicação de "drogas de estilo de vida", cujo objetivo não é fundamentalmente tratar uma doença, condições consideradas riscos de vida, à saúde, ou patológicas, mas aprimorar determinadas performances ou aparências corporais e tratar problemas que poderiam dificultar a vida das pessoas, como disfunção erétil ou calvície, por exemplo (Dumit, 2012; Loe, 2001; Mamo; Fishman, 2001).

Como argumenta Nucci (2012), as pílulas anticoncepcionais hormonais utilizadas, desde sua criação, no dia a dia, por mulheres saudáveis - podem ser aproximadas desse conceito de "drogas de estilo de vida". No caso das "novas gerações" de pílulas, esse aspecto se torna ainda mais evidente ao observarmos o marketing dos laboratórios farmacêuticos, que destaca possíveis efeitos secundários potencialmente desejáveis que as novas pílulas poderiam causar.

Do mesmo modo, nas reportagens publicadas em revistas e jornais brasileiros sobre os implantes, possíveis efeitos colaterais são destacados e tornam-se atrativos. Além de garantirem a contracepção, os implantes teriam como efeitos secundários a diminuição da celulite, a perda de peso e ganho de massa muscular, o aumento da libido, a redução da acne, a amenorreia (ausência de menstruação) e, consequentemente, a redução de problemas de humor relacionados à menstruação, como a chamada TPM, tensão pré-menstrual (Nucci, 2012). O trecho abaixo, retirado da reportagem "O chip da Moda", de 2013, publicado na Revista Planeta, explicita a questão:

Muitas vezes se evita tomar uma medicação devido às suas contraindicações. Poucos são os casos, entretanto, em que os possíveis efeitos colaterais acabam

${ }^{29}$ Ver http://drmm.com.br/. 
se tornando atrativos e ofuscando os propósitos originais do remédio. É o que acontece com os implantes hormonais - mais conhecidos como "chips da beleza”. Com frequência eles ganham espaço na mídia com declarações de usuárias que perderam peso, viram as celulites diminuir e a massa muscular aumentar, potencializando também a libido. (Mesquita, 2013).

Não apenas as revistas e jornais, mas também o site da Elmeco e sua página no Facebook ressaltam efeitos positivos que os implantes teriam sobre o humor, como é possível ver na Figura 5:

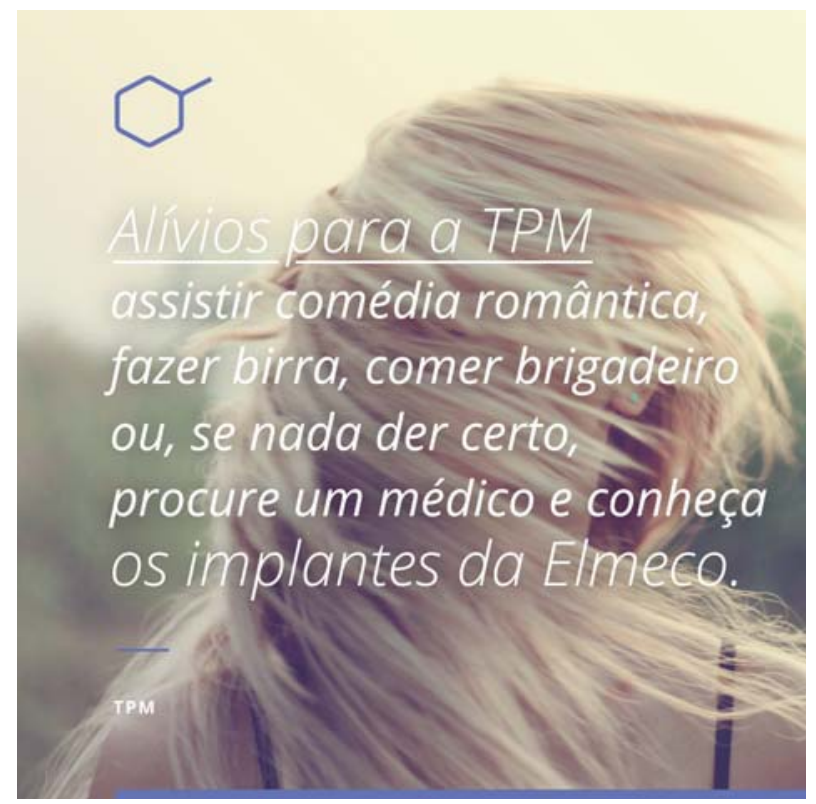

Figura 5. IPM e implantes (fonte: página da Elmeco no facebook ${ }^{30}$ ).

Em Menstruação, a sangria inútil, Elsimar Coutinho (1996) defende que, no estado de "natureza", as fêmeas estão frequentemente grávidas ou amamentando, e, portanto, sem menstruar. Tal como vivenciada pelas mulheres

${ }^{30}$ Ver https://www.facebook.com/elmeco. 
contemporâneas, que têm uma taxa de fecundidade muito menor do que as gerações anteriores, a menstruação seria um fenômeno recorrente do controle que a sociedade foi capaz de exercer, com bastante eficiência, sobre a fertilidade humana (Manica, 2009).

Desde o surgimento da contracepção hormonal, na década de 1960, teria sido possível um uso contínuo dos hormônios que permitisse, para além do efeito contraceptivo, "suspender" os sangramentos menstruais. Contudo, a formulação elaborada compreendeu a adoção de um regime de uso de hormônios em forma de pílulas orais, a serem tomadas uma vez ao dia por 21 dias consecutivos, com uma interrupção subsequente de 7 dias (através de uma pausa na ingestão das pílulas ou a utilização de um placebo), durante os quais deveria ocorrer um sangramento similar ao menstrual (Oudshoorn, 1999).

Esse sangramento não é considerado pelos médicos uma menstruação no sentido convencional, e sim um efeito da queda brusca da taxa dos hormônios que estavam sendo ingeridos. Trata-se, acima de tudo, de uma espécie de mimese do que ocorreria "naturalmente" - efeito que foi absolutamente fundamental para a aceitação social da pílula (Oudshoorn, 1999; Tone, 2001; Watkins, 1998). Uma interrupção prolongada dos sangramentos que não fosse devida à gestação, potencialmente possível com a ingestão contínua dessas substâncias, seria atribuída a algum tipo de problema de saúde ou mesmo a uma intervenção excessiva, indesejada e/ou insegura no corpo feminino.

A primeira pílula anticoncepcional foi, portanto, deliberadamente formatada para reproduzir os sangramentos menstruais, em função da sua viabilidade comercial e mercadológica e dos embates nos quais se disputavam sentidos sobre o corpo reprodutivo feminino e suas peculiaridades. Desse modo, a tão almejada desvinculação entre sexualidade e reprodução tornou-se possível de maneira relativamente discreta e eficiente. Preciado (2013, p. 209-210) caracteriza essa manobra de produção de uma "tecnomenstruação" como derivada de um princípio de "biocamuflagem", que ao mesmo tempo em que possibilita a contracepção, contribui para a produção "farmacopornográfica" do gênero no caso, corpos "tecnofemininos" supostamente "naturais".

Ao perceber a restrição colocada pela obrigatoriedade de "mimetizar" os sangramentos, Coutinho investiu no estudo e desenvolvimento de técnicas alternativas (como principalmente os injetáveis e implantes subcutâneos) e também na sua legitimação perante as usuárias e a opinião pública em geral. Como declara ao ser entrevistado para a reportagem da Revista Planeta: 
"Sou precursor da ideia de que a mulher pode escolher não menstruar, porque isso é um desperdício de sangue precioso que elas podem usar em doação" (Mesquita, 2013). Desse modo, a supressão da menstruação não deveria ser temida, mas desejada, como fica claro na reportagem publicada no jornal Folha de S. Paulo sobre os "milagres" realizados pelo implante:

"Primeiro, você desincha. Depois, dá uma secada, perde celulite, ganha músculo, seu corpo fica duro e a textura da pele, mais firme", descreve a modelo Talytha Pugliesi. Ela atribui o milagre ao implante à base de progesterona colocado há três anos. Pugliesi, 30, viu a medida do seu quadril cair de 91 para 88 centímetros. De quebra, o canudo enfiado sob sua pele a livrou da menstruação. (Bilenky, 2012, grifo nosso).

O pressuposto básico para o funcionamento eficaz do implante é de que haverá uma administração contínua de hormônios pela liberação subcutânea progressiva. Nesse sentido, há uma mudança fundamental em relação à formatação da contracepção oral, que permite os sangramentos mensais em sua interrupção periódica. ${ }^{31}$ Assim, a estabilização dessa técnica dos implantes envolveu necessariamente uma positivação da ausência dos sangramentos, a defesa da sua obsolescência e "inutilidade", quando não sua patologização (Manica, 2011). Após muito investimento na difusão dessas ideias e valores, movimento do qual Elsimar Coutinho participou ativamente, a supressão da menstruação através do uso de implantes, mas também de outros métodos como as pílulas anticoncepcionais hormonais de uso contínuo, ganha cada vez mais adeptas (Nucci, 2012).

Em contrapartida, há também muita resistência a técnicas como essas e movimentos de valorização da experiência da menstruação, que inclusive recusam radicalmente o uso de hormônios sintéticos e outros procedimentos que intervenham sobre o corpo e os ciclos férteis femininos, frequentemente compreendidos como "naturais". Chris Bobel (2010), por exemplo, analisa o que chama de movimentos de "ativismo menstrual" nos Estados Unidos, que envolvem desde a ampliação da visibilidade das experiências pessoais com a menstruação até a exposição efetiva de imagens e performances envolvendo o sangue menstrual. No Brasil, ainda que incipientes, existem manifestações que preconizam a valorização do corpo feminino, representado pela menstruação. Há também

31 Caso seja bem-sucedida nos seus propósitos, a tecnologia dos microchips permitirá acrescentar os efeitos de interrupção programada da pílula aos da ação prolongada dos implantes subcutâneos.

Horizontes Antropológicos, Porto Alegre, ano 23, n. 47, p. 93-129, jan./abr. 2017 
movimentos pela positivação de experiências corporais como gestação, parto e amamentação (ver Alzuguir; Nucci, 2015; Carneiro, 2014; Tornquist, 2002).

$\mathrm{Na}$ reportagem de setembro de 2015 do jornal O Globo, os implantes subcutâneos aparecem caracterizados como "chip fashion" ou "chip da dieta". Entre os especialistas entrevistados, o endocrinologista Fabiano Serfaty, que trabalha em parceria com Elsimar Coutinho, explica que: "O implante ganhou o apelido de 'chip fashion' porque é muito usado por modelos, devido à praticidade e à capacidade de mudar o corpo e a vida da mulher quando indicado de forma correta" (Ribeiro, 2015).

Associados a modelos e beleza, os implantes são ligados também, nas reportagens analisadas, a um estilo de vida "fitness", como é possível ver na Figura 6 e no trecho abaixo, publicado na revista Veja Brasília:

\section{O chip da força} Apesar das ressalvas de outros profissionais de saúde, médico baiano
conquista clientes no DF com tratamento hormonal que deixa o corpo
sarado

Por: Hédio Ferreira Jûnior $\bigcirc$ 09/01/2015 às 11:26 - Atualizado em 10/01/2015 às 08:32
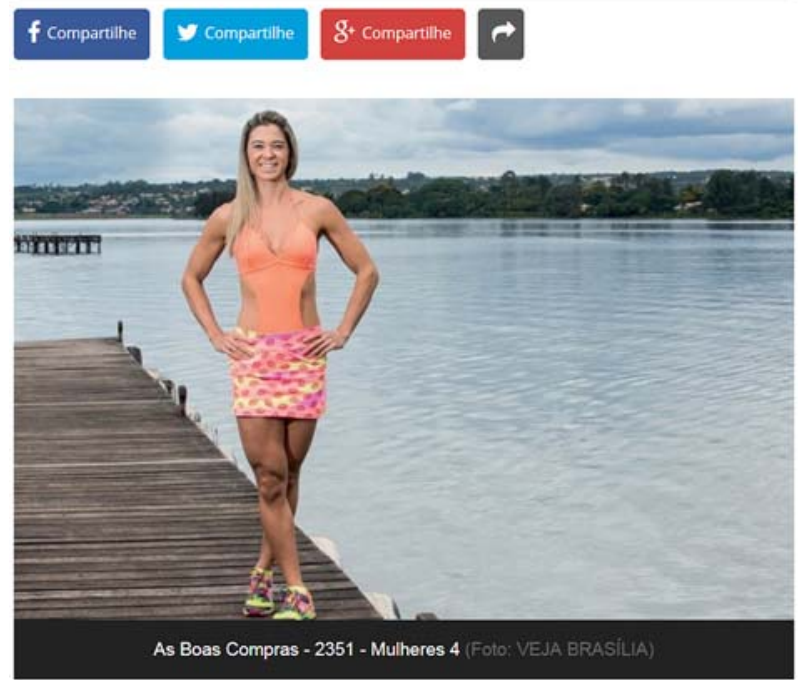

Figura 6. Chip da força (Ferreira Júnior, 2015). 
Aos 40 anos, a empresária Karine Midori Togawa cuida da casa, da família e de uma agência dos Correios no Setor de Indústrias Gráficas (SIG). Ao mesmo tempo, segue uma disciplina quase religiosa entre os adeptos do mundo fitness. Para dar conta do recado e do corpão que põe no chinelo meninas com metade da sua idade, ela acorda todos os dias às 7 horas, a tempo de fazer aula de ginástica localizada em uma academia da cidade, segue uma dieta controlada por um nutricionista e leva no corpo um chip que potencializa sua disposição. Karine é uma das centenas de pacientes brasilienses do ginecologista baiano Elsimar Coutinho, responsável, em parceria com seu sócio Luiz Carlos Calmon, por um tratamento de implante hormonal que tem causado frisson entre as bem vividas da capital. O método promete extinguir os incômodos da menstruação, eliminar celulite, elevar a libido e a disposição no dia a dia e, de quebra, propiciar pernas musculosas, abdômen trincado e braços definidos. (Ferreira Júnior, 2015, grifo nosso).

Importante notar, porém, como o chip potencializaria a disposição de sua usuária, pois é preciso também disciplinar-se, controlando a alimentação e realizando exercícios físicos, para que os hormônios tenham o efeito desejado. Nas palavras da entrevistada da reportagem acima, Karine: "O implante adora treino, dieta e um aeróbico" (Ferreira Júnior, 2015). Além dos exercícios físicos e alimentação, a ação dos hormônios sobre a celulite, a libido e os músculos pode ser atribuída aos efeitos da testosterona, cujo uso em mulheres é controverso, como veremos adiante.

Nas reportagens analisadas, percebe-se um esforço em diferenciar os usos legítimos dos implantes (ou seja, aqueles com indicação médica) dos ilegítimos (apenas para fins estéticos). Ao mesmo tempo em que confirma - e valoriza - os benefícios estéticos que o uso dos implantes possibilita, Coutinho diferencia a sua prática médica da prática de esteticistas:

"Atendo de 20 a 30 pacientes por dia e $90 \%$ da minha clientela usa o implante para questões médicas. [...]” Mas explica que alguns hormônios, como a testosterona e a gestrinona (que é anabolizante de proteína), podem gerar efeitos estéticos, pois facilitam o desenvolvimento de músculos e a queima de gordura. "Eu pessoalmente não uso na área de beleza porque não sou esteticista. Mas os implantes poderiam ser indicados para estética, contanto que o médico lembre que seu primeiro dever é não fazer mal. Usar medicação para estética pode fazer mal. Além do que a beleza é muito subjetiva, vai da moda", argumenta. (Mesquita, 2013).

O aspecto de "estilo de vida" dos implantes fica, portanto, camuflado em indicações médicas que podem envolver justificativas bastante flexíveis. 
Embora gravidez e menopausa não configurem, a princípio, patologias, a contracepção, reposição hormonal ou mesmo o desejo de regular o ciclo menstrual (uma das primeiras indicações para a pílula, na ocasião de seu surgimento) podem cumprir essa função de fornecer uma legitimidade médica para a utilização dos implantes.

\section{Os usos de hormônios androgênicos em implantes subcutâneos}

Um dos "perigos" que ronda o uso dos implantes com testosterona, e que é explorado nas reportagens, é o da usuária se "masculinizar". Esse ponto é destacado já no título de uma reportagem publicada na Folha de S. Paulo em 2012: "Implante hormonal pode 'masculinizar' a paciente, afirma endocrinologista". Na reportagem, a endocrinologista Ieda Therezinha Verreschi, membro do Conselho Regional de Medicina de São Paulo, é entrevistada, e posiciona-se de forma contrária ao uso dos implantes para fins estéticos, ressaltando a possibilidade de "desfeminilização" através do uso dos hormônios: "O conselho não apoia o uso de hormônio em implante para melhorar o aspecto físico. [Esse tratamento] só aumenta a musculatura, 'desfeminiliza' e cria pelo. Fica um 'monstrinho' a criatura” (Bilenky, 2012).

O potencial "masculinizador" viria de hormônios como a testosterona e a gestrinona que, de acordo com a reportagem, seriam responsáveis por aumentar a libido das mulheres, mas também por efeitos colaterais indesejáveis, como perda de cabelo e mudança na voz. Conforme informações do site da Elmeco,

Os efeitos colaterais da gestrinona são observados mais nas mulheres jovens e refletem a sua ação androgênica. Seborréia, acne, queda de cabelo, rouquidão, ganho muscular, são efeitos que podem ser atenuados pelo uso da espironolactona na dose de $50 \mathrm{mg}$, duas vezes ao dia. ${ }^{32}$

Oudshoorn (2003) nomeia esse tipo de solução compensatória (o uso de um comprimido para minimizar determinados efeitos produzidos pelos implantes) como um "monstro tecnológico". O mecanismo desenvolvido para o tratamento desejado é complexo demais da perspectiva do usuário, e isso compromete a eficácia da técnica. Ou seja, nesse caso, precisar compensar os

32 Ver http://www.voulta.com/clientes/elmeco/produtos/. 
efeitos colaterais indesejáveis da testosterona com o uso de mais um tipo de medicação, a espironolactona (fazendo uma combinação que envolve implante + comprimidos diários) não configuraria um tipo de tratamento tão desejável quanto seria o que possibilitasse resolver todas as questões necessárias com o uso de um simples comprimido, ou de um implante, cujos efeitos não precisassem ser monitorados, corrigidos ou modificados ao longo do processo. Contudo, como vimos, nas usuárias dos implantes da Elmeco que apresentam esses sintomas, essa solução é empregada.

Os implantes de testosterona são disponibilizados pela Elmeco para homens e mulheres, e utilizados na prática clínica possivelmente com complementos como os comprimidos, no caso de mulheres que apresentam sinais indesejáveis de virilização como as alterações na voz e nos pelos corporais.

Ambos (pelos e voz) são sinais mais marcantes de expressões corporais ligadas a gênero. Voz mais grossa e corpos mais peludos são características entendidas como masculinas. A depilação e redução da visibilidade dos pelos em determinadas partes dos corpos femininos são parte importante das tecnologias do sexo (cf. Preciado, 2014) que envolvem a produção de corpos femininos. Tratamentos com hormônios virilizantes, como os disponibilizados pela Elmeco, têm que lidar com efeitos colaterais sobre esses aspectos. Por outro lado, outros efeitos desses mesmos hormônios (sobretudo a testosterona e a gestrinona) sobre, por exemplo, a libido, a celulite e a musculatura não são tão problematizados pelas usuárias dos implantes. Pelo contrário, são positivados e divulgados como efeitos complementares (e desejáveis) do tratamento.

Em Vivendo sem regras e sem TPM!, Elsimar Coutinho (2007) reúne registros de vários casos de pacientes que atendeu em seus consultórios, descrevendo as queixas iniciais e os resultados obtidos por elas com os tratamentos disponibilizados com os implantes da Elmeco. Problemas de seborreia e acne decorrentes do uso dos implantes de gestrinona foram relatados em diversos casos. Por exemplo, o de Giulia (Coutinho, 2007, p. 93-94), que acabou substituindo a gestrinona por implantes de elcometrina e testosterona; e de Marinalva (Coutinho, 2007, p. 175-176), para quem foi receitada a espironolactona como solução.

Em muitos relatos também Coutinho procura demonstrar, e defender, os efeitos positivos da testosterona sobre a libido feminina. ${ }^{33}$ Conta a história de Marianne, que se queixava de depressão e falta de interesse sexual, prejudicial

33 Acerca do uso de testosterona por mulheres e sexualidade, ver Faro (2016). 
ao seu casamento com um marido "fogoso". Após fazer exames de sangue que detectaram níveis baixos de estradiol e testosterona, ela foi tratada com implantes dessas duas substâncias. Segundo Coutinho, após duas semanas ela lhe telefonara para contar que o efeito dos implantes sobre a libido foi bom, tendo-lhe devolvido o "apetite sexual". Coutinho (2007, p. 135-136) cita a conclusão da paciente sobre seu tratamento: "Devo a esses implantes a felicidade nos últimos dez anos do meu casamento no que se refere à parte sexual, que se encontrava praticamente zerada."

O caso de Dona Clarice também é interessante nesse sentido. Paciente de reposição hormonal há muitos anos, ela o procurou para que pudesse continuar a fazê-lo mesmo depois dos 73 anos, quando outros médicos passaram a desaconselhar a continuidade desse tratamento por causa dos riscos de câncer no útero e nas mamas. Aos 78 anos, cinco utilizando os implantes, e após ter realizado uma histerectomia, Clarice teria então pedido para "aumentar um pouco a dose de testosterona para melhorar a libido". Passou, então, a usar três implantes de testosterona, combinados com três de estradiol. Segundo Coutinho (2007, p. 203-204), três anos depois, o tratamento com testosterona foi reduzido para apenas dois implantes, "porque o marido não a acompanhava mais como antes".

Como observa Oudshoorn (1999), no início do desenvolvimento da endocrinologia os hormônios sexuais eram vistos como exclusivamente masculinos ou femininos. Essa concepção foi gradualmente se modificando até uma abordagem "quantitativa" dos hormônios sexuais, em que ambos os organismos poderiam possuir características tanto "femininas" quanto "masculinas", em diferentes graus. Ainda assim, a ideia de que a testosterona é a representação máxima da masculinidade permanece não apenas no senso comum, mas permeia o discurso e a prática médica e científica. ${ }^{34}$

Nas reportagens analisadas, é possível notar uma preocupação com a "masculinização" das usuárias por conta da testosterona, já que esta seria o hormônio essencialmente "masculino", e seu uso por mulheres constituiria uma espécie de violação. Na década de 1980, Elsimar Coutinho foi denunciado no Conselho Regional de Medicina da Bahia, acusado de utilizar substâncias masculinizantes em suas pacientes, tendo sido absolvido do processo

\footnotetext{
34 Ver, por exemplo, Faro (2016), bem como as discussões recentes a respeito da Deficiência Androgênica do Envelhecimento - DAEM em Rohden (2011), Tramontano (2012), Tramontano e Russo (2015) e Thiago (2012).
}

Horizontes Antropológicos, Porto Alegre, ano 23, n. 47, p. 93-129, jan./abr. 2017 
(Manica, 2009). Foi, talvez, após esse processo que Coutinho passou a defender mais enfaticamente a teoria de que ambos os sexos possuem hormônios "masculinos" (como a testosterona) e "femininos" (como o estrogênio) e que sua utilização através dos implantes da Elmeco não constitui uma mudança significativa sobre a feminilidade ou a masculinidade.

Assim, apesar das controvérsias, como é possível notar na imagem abaixo (Figura 7), há um esforço por parte da Elmeco em naturalizar o uso da testosterona em mulheres:

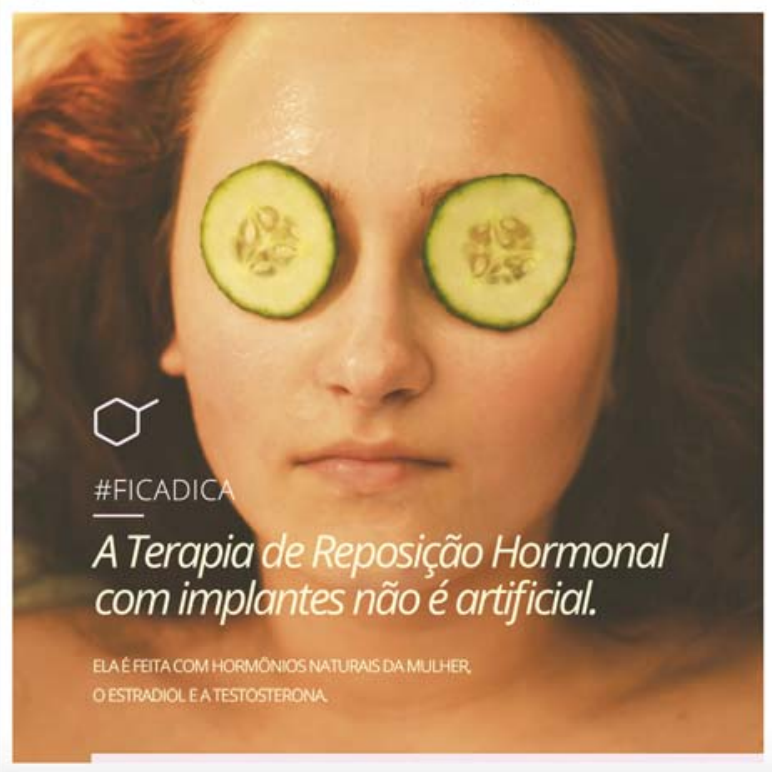

Figura 7. Natural versus artificial (fonte: página da Elmeco no Facebook ${ }^{35}$ ).

35 Ver https://www.facebook.com/elmeco. 
Além da oposição feminino versus masculino ("hormônios naturais da mulher"), a imagem aciona também distinções entre artificial versus natural ("a terapia não é artificial" e "é feita com hormônios naturais da mulher"). $\mathrm{O}$ estradiol e a testosterona que compõem os implantes da Elmeco são hormônios considerados "naturais" e por isso chamados de "bioidênticos", como Coutinho explica no trecho da reportagem a seguir:

"Os implantes hormonais de testosterona e estradiol são bioidênticos, ou seja, são iguais aos hormônios produzidos pelo próprio organismo, no que diz respeito à estrutura molecular", explica o Dr. Elsimar Coutinho. (Braga, [s.d.]).

A ideia de que o uso dos hormônios "bioidênticos" contidos nos implantes seria mais "natural" do que outras administrações hormonais - como as pílulas anticoncepcionais tradicionais, por exemplo, reforça a persistência da oposição entre "natureza" e "cultura" para qualificar questões relacionadas a corpo, gênero, hormônios e tecnociência. No caso, a remissão à "bioidentidade" procura produzir uma aproximação ao que seria considerado "mais natural" - a não intervenção sobre os corpos. E, sobretudo, neutralizar as críticas de que o uso de testosterona pelas mulheres (pacientes/clientes/público-alvo) representaria qualquer risco à sua feminilidade, sua identidade de gênero, $o$ que reforça também o caráter instável da diferença sexual. ${ }^{36}$

\section{Consideracõoes finais: implantes, hormônios e a microprostética de gênero}

Movimento "sofisticado" da tecnologia, tentar apresentar-se exatamente como natureza (Preciado, 2014, p. 168). No entanto, como aponta Preciado, numa releitura importante da contribuição de Haraway (2000) para pensar as relações entre (pós-)feminismo e a tecnociência, mecanismos como esses mobilizam as oposições estruturantes do pensamento ocidental com o objetivo de fixar determinadas funções aos objetos sociotécnicos (como os hormônios e os implantes), em detrimento de muitas outras possíveis. As mesmas bio/ cibertecnologias que resultam de estruturas de poder muito específicas concentram "bolsões de resistência" a esse mesmo poder (Preciado, 2014). Ao

\footnotetext{
${ }^{36}$ Noção presente também no discurso tradicional da medicina, ver por exemplo Rohden (2001).
} 
recusar uma posição de demonização essencialista da tecnologia, com a figura do ciborgue, Haraway abre caminho para experimentações como a que Preciado (2013) encarna em Testo junkie.

Ao falar sobre seu uso "subversivo" do gel de testosterona na proposta de uma "autointoxicação voluntária", Preciado comenta como a bula do medicamento "traficado" (Testogel) constitui um manual de microfascismo de gênero: pressupõe que seu usuário seja um homem cis em busca da reposição hormonal por uma deficiência androgênica, como a andropausa, por exemplo. Da mesma maneira, a pílula pressupõe, e (re)constitui, a feminilidade dos corpos de mulheres cis, cuja heterossexualidade tem efeitos reprodutivos que os hormônios sintéticos foram convocados a resolver.

$\mathrm{O}$ uso controverso da testosterona, junkie, subversivo à prescrição e que recusa os critérios e procedimentos que envolveriam um acesso legalizado e medicalizado à transexualização, levam Preciado a transitar pelas ficções somático-políticas de gênero, experimentando as alterações corporais provocadas pelos hormônios e seus efeitos para problematizar os pressupostos encarnados na ideia de uma diferença sexual binária estável. ${ }^{37}$

Podemos considerar, a partir da discussão proposta até aqui, o quanto a forma de administração da substância (testosterona em gel) possibilitou o desafio proposto por Preciado à microprostética de gênero do regime farmacopornográfico. A disponibilidade do gel e sua facilidade de uso (inclusive "abusivo") constituem uma tecnopolítica que favorece seu uso subversivo. Para os implantes e chips subcutâneos, essa possibilidade de subversão efetiva dependeria de estabelecer outras associações (Latour, 2005) para além dos traficantes do gel e do "desejo de trânsito" (Preciado, 2013, p. 143) - médicos,

\footnotetext{
37 "For a body accustomed to regulating its hormonal metabolism in terms of the production of estrogen, the intentional increasing of the level of testosterone in the blood constitutes an endocrinal reprogramming. The slightest hormonal change affects all the functions of the body: the desire to eat and to fuck, circulation and the absorption of minerals, the biological rhythms regulating sleep, the capacity for physical exertion, muscular tone, metabolism, the sense of smell and taste - in fact, the entire biochemical physiology of the organism. None of these modifications can be qualified as masculine. But of all the mental and physical effects caused by self-intoxication based on testosterone in gel form, the feeling of transgressing limits of gender that have been socially imposed on me was without a doubt the most intense. The new metabolism of testosterone in my body wouldn't be effective in terms of masculinization without the previous existence of a political agenda that interprets these changes as an integral part of a desire - controlled by the pharmacopornographic order - for sex change. Without this desire, without the project of being in transit from one fiction of sex to another, taking testosterone would never be anything but a molecular becoming" (Preciado, 2013, p. 143).
}

Horizontes Antropológicos, Porto Alegre, ano 23, n. 47, p. 93-129, jan./abr. 2017 
enfermeiras, produtores dos implantes e seu aparato sociotécnico, e a disposição para extrapolar as posologias indicadas.

As discussões sobre virilização e efeitos colaterais da testosterona (Faro, 2016) demonstram a instabilidade e a necessidade de constante monitoramento das quantidades de substâncias que são administradas pela via subcutânea, com os implantes (e com os eventuais chips também). Nesse processo, como vimos, não somente os hormônios se apresentam como vias de controle da fertilidade e dos corpos, como também seus efeitos são modulados através da valorização ou desvalorização de determinados aspectos ligados a gênero e sexualidade (fertilidade, menstruação, músculos, libido, pelos e voz, por exemplo).

Assim, os implantes subcutâneos, analógicos e digitais, tais como apresentados pelo material empírico aqui trazido (isto é, a partir da Elmeco, da Fundação Bill \& Melinda Gates, suas convergências e divergências), permitem problematizar os desdobramentos do desenvolvimento tecnocientífico, farmacopornográfico, dos hormônios sexuais. Seus diversos fluxos possíveis em corpos fundamentalmente diversos (em termos de sexo, raça, nacionalidade, orientação sexual, condição de classe, etc.) indicam ao mesmo tempo os limites e potências que envolvem nossas dinâmicas vitais, e suas (im)possibilidades.

\section{Referências}

AGÊNCIA NACIONAL DE VIGILÂNCIA SANITÁRIA. Subsídios à discussão sobre a proposta de regulamentação para farmácias magistrais. Revista de Saúde Pública, São Paulo, n. 39, v. 4, p. 691-694, 2005.

ALZUGUIR, F.; NUCCI, M. Maternidade mamífera? Concepções sobre natureza e ciência em uma rede social de mães. Mediações, Londrina, v. 20, n. 1, p. 217-238, 2015.

BASULTO, D. This amazing remote-controlled contraceptive microchip you implant under your skin is the future of medicine. The Washington Post, 17 jul. 2014. Disponível em: <https://www.washingtonpost.com/news/innovations/ $\mathrm{wp} / 2014 / 07 / 17 /$ this-amazing-remote-controlled-contraceptive-microchip-youimplant-under-your-skin-is-the-future-of-medicine/>. Acesso em: $31 \mathrm{dez} .2015$. 
BERQUÓ, E. (Org.). Sexo \& vida: panorama da saúde reprodutiva no Brasil. Campinas: Editora da Unicamp, 2003.

BILENKY, T. Implante hormonal pode 'masculinizar' a paciente, afirma endocrinologista. Folha de S. Paulo, São Paulo, 27 nov. 2012. Disponível em: $<$ http://www1.folha.uol.com.br/equilibrioesaude/2012/11/1191507-implantehormonal-pode-masculinizar-a-paciente-afirma-endocrinologista.shtml $>$. Acesso em: 31 dez. 2015.

BOBEL, C. New blood: third-wave feminism and the politics of menstruation. New Brunswick: Rutgers University Press, 2010.

BRAGA, S. Implante hormonal anticonceptivo: mais segurança e menos TPM. Vila Mulher, [s.d.]. Disponível em: <http://www.vilamulher.com.br/bemestar/comportamento/implante-hormonal-anticonceptivo-mais-seguranca-emenos-tpm-11-1-69-814.html>. Acesso em: 31 dez. 2015.

CARNEIRO, R. De perto e de longe do que seria natural, mais natural e/ ou humanizado: uma etnografia de grupos de preparo para o parto. In: FERREIRA, J.; FLEISCHER, S. (Org.). Etnografias em serviços de saúde. Rio de Janeiro: Garamond, 2014. p. 243-265.

CHIP anticoncepcional: como funciona e os benefícios. Mulher.com.br, [s.d.]. Disponível em: <http://www.mulher.com.br/11178/chip-anticoncepcionalcomo-funciona-e-os-beneficios>. Acesso em: 31 dez. 2015.

CONRAD, P. The medicalization of society: on the transformation of human conditions into treatable disorders. Baltimore: The John Hopkins University Press, 2007.

CORRÊA, S. O Norplant nos anos 90: peças que faltam. Revista Estudos Feministas, Florianópolis, n. esp., p. 86-98, segundo sem. 1994.

CORRÊA, S. Anticoncepcionais injetáveis na perspectiva feminista: o debate histórico e os novos desafios. In: ARILHA, M.; CITELI, M. T. Políticas, mercado, ética: demandas e desafios no campo da saúde reprodutiva. São Paulo: Editora 34: Comissão de Cidadania e Reprodução, 1998. 
COUTINHO, E. Menstruação, a sangria inútil. São Paulo: Gente, 1996.

COUTINHO, E. Vivendo sem regras e sem TPM!. São Paulo: Landscape, 2007.

COUTINHO, E. Autobiografia. [s.d.]. Manuscrito não publicado.

DACACH, S.; ISRAEL, G. As rotas do Norplant: desvios da contracepção. Rio de Janeiro: Redeh, 1993.

DUMIT, J. Drugs for life: how pharmaceutical companies define our health. Durham: Duke University Press, 2012.

FARO, L. "Mulher com bigode nem o diabo pode": um estudo sobre testosterona, sexualidade feminina e medicalização. 2016. Tese (Doutorado em Saúde Coletiva)-Instituto de Medicina Social, Universidade do Estado do Rio de Janeiro, Rio de Janeiro, 2016.

FERREIRA JUNIOR, H. O chip da força. Veja Brasília, 9 jan. 2015. Disponível em: <http://vejabrasilia.abril.com.br/materia/consumo/o-chip-daforca/>. Acesso em: 31 dez. 2015.

FONSECA SOBRINHO, D. da. Estado e população: uma história do planejamento familiar no Brasil. Rio de Janeiro: Rosa dos Tempos: FNUAP, 1993.

FOUCAULT, M. História da sexualidade I: a vontade de saber. Rio de Janeiro: Graal, 1977.

HARAWAY, D. Manifesto ciborgue: ciência, tecnologia e feminismo-socialista no final do século XX. In: SILVA, T. T. da. Antropologia do ciborgue: as vertigens do pós-humano. Belo Horizonte: Autêntica, 2000. p. 37-129.

JARDIM, R. O controle da reprodução: estudo etnográfico da prática contraceptiva de implantes subcutâneos na cidade de Porto Alegre. 2009. Dissertação (Mestrado em Antropologia Social)-Instituto de Filosofia e Ciências Humanas, Universidade Federal do Rio Grande do Sul, Porto Alegre, 2009. 
KINKEAD, G. A contraceptive implant with remote control. MIT Technology Review, 4 jul. 2014. Disponível em: <https://www.technologyreview.com/ s/528121/a-contraceptive-implant-with-remote-control/>. Acesso em: $31 \mathrm{dez}$. 2015 .

LATOUR, B. Reassembling the social: an introduction to actor-networktheory. New York: Oxford University Press, 2005.

LEE, D. 'Remote control' contraceptive chip available 'by 2018'. BBC, 7 jul. 2014. Disponível em: <http://www.bbc.com/news/technology-28193720>. Acesso em: 31 dez. 2015.

LOE, M. Fixing broken masculinity: Viagra as a technology for the production of gender and sexuality. Sexuality and Culture, New York, v. 3, n. 5, p. 97-125, 2001.

MAMO, L.; FISHMAN, J. Potency in all the right places: Viagra as a technology of the gendered body. Body \& Society, London, n. 7, p. 13-35, 2001.

MANICA, D. T. Supressão da menstruação: ginecologistas e laboratórios farmacêuticos re-apresentando natureza e cultura. 2003. Dissertação (Mestrado em Antropologia Social)-Instituto de Filosofia e Ciências Humanas, Universidade Estadual de Campinas, Campinas, 2003.

MANICA, D. T. Contracepção, natureza e cultura: embates e sentidos na etnografia de uma trajetória. 2009. Tese (Doutorado em Antropologia Social)-Instituto de Filosofia e Ciências Humanas, Universidade Estadual de Campinas, Campinas, 2009.

MANICA, D. T. A desnaturalização da menstruação: hormônios contraceptivos e tecnociência. Horizontes Antropológicos, Porto Alegre, ano 17, n. 35, p. 198 226, 2011.

McNAMEE, D. Contraceptive microchip: could it revolutionize global birth control?. MNT, 7 jul. 2015. Disponível em: $<$ http://www.medicalnewstoday. com/articles/279323.php>. Acesso em: $31 \mathrm{dez} .2015$. 
MESQUITA, R. V. O chip da moda. Revista Planeta, 27 fev. 2013. Disponível em: <http://www.revistaplaneta.com.br/o-chip-da-moda/>. Acesso em: 31 dez. 2015.

NATHANSON, L. G. Consultando médicos na televisão: meios de comunicação, mulheres e medicina. 2003. Tese (Doutorado em Comunicação Social)-Faculdade de Comunicação, Universidade Federal da Bahia, Salvador, 2003.

NUCCI, M. Seria a pílula anticoncepcional uma droga de "estilo de vida"? Ensaio sobre o atual processo de medicalização da sexualidade. Sexualidade, Saúde e Sociedade, Rio de Janeiro, n. 10, p. 124-139, 2012.

OSIS, M. J. M. D. Atenção integral à saúde da mulher, o conceito e o programa: história de uma intervenção. 1994. Dissertação. (Mestrado em Antropologia Social)-Instituto de Filosofia e Ciências Humanas, Universidade Estadual de Campinas, Campinas, 1994.

OSIS, M. J. M. D. Paism: um marco na abordagem da saúde reprodutiva no Brasil. Cadernos de Saúde Pública, Rio de Janeiro, v. 14, sup. 1, p. 25-32, 1998.

OUDSHOORN, N. Beyond the natural body: an archeology of sex hormones. London: Routledge, 1999.

OUDSHOORN, N. The male pill: a biography of a technology in the making. Durham: Duke University Press, 2003.

PETRYNA, A. When experiments travel: clinical trials and the global search for human subjects. Princeton: Princeton University Press, 2009.

PETRYNA, A. Experimentalidade: ciência, capital e poder no mundo dos ensaios clínicos. Horizontes Antropológicos, Porto Alegre, ano 17, n. 35, p. $127-10,2011$.

PITANGUY, J. Feminist politics and reproductive rights: the case of Brazil. In: SEN, G.; SNOW, R. Power and decision: the social control of reproduction. Boston: Harvard University Press, 1994. p. 101-122. 
PRECIADO, B. Testo junkie: sex, drugs, and biopolitics in the pharmacopornographic era. New York: Feminist Press, 2013.

PRECIADO, B. Tecnologias do sexo. In: PRECIADO, B. Manifesto contrassexual. São Paulo: n-1 edições, 2014. p. 147-168.

REDE Municipal adquire implantes contraceptivos de longa duração para ampliar gama do Planejamento Reprodutivo. Prefeitura de São Paulo, $11 \mathrm{fev.}$ 2016. Disponível em: $<$ http://www.prefeitura.sp.gov.br/cidade/secretarias/ saude/noticias/?p=211815>. Acesso em: 15 fev. 2016.

RIBEIRO, C. Como funciona o controverso implante hormonal conhecido como 'chip fashion' ou 'chip da dieta'. O Globo, Rio de Janeiro, 20 set. 2015. Disponível em: $<$ http://oglobo.globo.com/ela/beleza/como-funcionacontroverso-implante-hormonal-conhecido-como-chip-fashion-ou-chip-dadieta-17531644>. Acesso em: 31 dez. 2015.

ROHDEN, F. Uma ciência da diferença: sexo e gênero na medicina da mulher. Rio de Janeiro: Editora Fiocruz, 2001.

ROHDEN, F. "O homem é mesmo a sua testosterona": promoção da andropausa e representações sobre sexualidade e envelhecimento no cenário brasileiro. Horizontes Antropológicos, Porto Alegre, ano 17, n. 35, p. 162196, 2011.

ROSE, N. A política da própria vida: biomedicina, poder e subjetividade no século XXI. São Paulo: Paulus, 2013.

SANABRIA, E. Le médicament, un objet evanescent: essai sur la fabrication et la consommation des substances pharmaceutiques. Techniques \& Culture, Paris, n. 52-53, p. 168-189, 2009.

SANTOS, L. G. dos. Politizar as novas tecnologias: o impacto sociotécnico da informação digital e genética. São Paulo: Editora 34, 2003.

SILVA, A. C. et al. Desafios para a rede nacional de laboratórios de vigilância sanitária: o caso dos medicamentos manipulados. Ciência \& Saúde Coletiva, Rio de Janeiro, v. 15, supl. 3, p. 3371-3380, 2010. 
THIAGO, C. da C. Hormônios, masculinidade e velhice: um estudo de sites de laboratórios farmacêuticos e associações médico-científicas. 2012. Dissertação (Mestrado em Saúde Coletiva)-Instituto de Medicina Social, Universidade do Estado do Rio de Janeiro, Rio de Janeiro, 2012.

TONE, A. Devices and desires: a history of contraceptives in America. New York: Hill and Wang, 2001.

TORNQUIST, C. Armadilhas da nova era: natureza e maternidade no ideário da humanização do parto. Revista Estudos Feministas, Florianópolis, n. 2, p. 483-492, 2002.

TRAMONTANO, L. "Continue a nadar": sobre testosterona, envelhecimento e masculinidade. 2012. Dissertação (Mestrado em Saúde Coletiva)-Instituto de Medicina Social, Universidade do Estado do Rio de Janeiro, Rio de Janeiro, 2012 .

TRAMONTANO, L.; RUSSO, J. O diagnóstico de Deficiência Androgênica do Envelhecimento Masculino e os (des)caminhos do desejo sexual masculino. Mediações, Londrina, v. 20, n. 1, p. 174-193, 2015.

VECCHIO, T. J. Birth control by injection: the story of Depo-Provera. New York: Vantage Press, 1993.

VENTURA, F. Para não engravidar, mulheres poderão usar este chip financiado por Bill Gates. Gizmodo Brasil, 8 jul. 2014. Disponível em: <http://gizmodo. uol.com.br/chip-implante-contraceptivo/>. Acesso em: 31 dez. 2015.

WATKINS, E. S. On the pill: a social history of oral contraceptives 19501970. Baltimore: The Johns Hopkins University Press, 1998.

WERNECK, C. Conheça o chip anticoncepcional. Dicas de Mulher, 5 set. 2013. Disponível em: <http://www.dicasdemulher.com.br/conheca-o-chipanticoncepcional/>. Acesso em: $31 \mathrm{dez} .2015$. 